\title{
Efficacy of Voriconazole in a Guinea Pig Model of Invasive Trichosporonosis
}

\author{
Carolina Serena, Félix Gilgado, Marçal Mariné, F. Javier Pastor, and Josep Guarro* \\ Unitat de Microbiologia, Facultat de Medicina i Ciències de la Salut, Universitat Rovira i Virgili, Reus, Spain
}

Received 11 January 2006/Returned for modification 13 February 2006/Accepted 15 March 2006

\begin{abstract}
We have evaluated the efficacy of voriconazole (VRC) in a systemic infection by Trichosporon asahii in immunosuppressed guinea pigs. VRC was more effective than amphotericin $B$ in prolonging survival and reducing tissue burden. The best results were obtained with VRC at $10 \mathrm{mg} / \mathrm{kg}$ of body weight/day.
\end{abstract}

Trichosporonosis is an uncommon but frequently fatal invasive infection of immunocompromised patients caused by Trichosporon spp. $(12,18,20,21)$. Trichosporon asahii is the most common species involved $(10,11,12,13)$. Trichosporonosis is generally treated with amphotericin $\mathrm{B}(\mathrm{AMB})$ or fluconazole, commonly with an unsatisfactory outcome $(1,4,6,9,12,22)$. In a previous study we also demonstrated, using a murine model of disseminated infection by $T$. asahii, that the efficacy of both drugs was very limited but improved when each of them was combined with micafungin (16).

The aim of this study was to determine whether other therapeutic alternatives would also be effective in the treatment of trichosporonosis. Since voriconazole (VRC) has demonstrated in vitro activity $(7,9,17,19)$ even against multidrug-resistant strains of $T$. asahii (8), and favorable outcomes in several clinical cases have been reported $(3,9)$, we have evaluated the effectiveness of this drug in a guinea pig model. The pharmacokinetics of VRC in guinea pigs makes these animals appropriate for testing of this drug (15).

We have tested two isolates of T. asahii, IHEM 17910, from a blood culture of a patient with posthepatitis medullar aplasia, and IHEM 9325, from the floor of a swimming pool. On the day of infection, 24-h cultures on Sabouraud dextrose agar (SDA) were suspended in sterile saline and filtered through sterile gauze to remove clumps of cells or hyphae. The resulting suspensions, containing $\geq 95 \%$ conidial forms (arthroconidia and blastoconidia), were adjusted to the desired inoculum based on hemocytometer counts and by serial plating on SDA to confirm viability.

MICs of AMB and VRC against the two strains used in the study were determined by using a broth microdilution method for yeasts (14) and were defined as the lowest concentration resulting in $100 \%$ inhibition of growth for $\mathrm{AMB}$ and $50 \%$ inhibition of growth for VRC.

We used Hartley albino guinea pigs weighing 450 to $500 \mathrm{~g}$, and the Animal Welfare Committee at our university approved the conditions. Neutropenia was induced by intraperitoneal administration of cyclophosphamide at $100 \mathrm{mg} / \mathrm{kg}$ of

\footnotetext{
* Corresponding author. Mailing address: Unitat de Microbiologia, Facultat de Medicina, Universitat Rovira i Virgili, Carrer Sant Llorenç, 21.43201 Reus, Spain. Phone: 977-759359. Fax: 977-759322. E-mail: josep .guarro@urv.net.
}

body weight on days $-3,-1,+1,+3,+8$, and $+13(5)$ Animals were challenged intravenously with $6 \times 10^{6} \mathrm{CFU}$ for strain IHEM 17910 and $1.2 \times 10^{7} \mathrm{CFU}$ for IHEM 9325 in $0.2 \mathrm{ml}$. During a preliminary study to establish the lethal dose, we tested inocula of $6 \times 10^{6}, 1.2 \times 10^{7}$, and $2 \times 10^{7}$ CFU, and we chose those inocula that produced an acute infection, with $100 \%$ of animals dying within 7 days of infection.

Groups of six animals were treated with VRC or AMB, both administered once a day. VRC was dissolved in polyethylene glycol and administered at $5 \mathrm{mg} / \mathrm{kg} /$ day (V5) or $10 \mathrm{mg} / \mathrm{kg} / \mathrm{day}$ (V10) orally. AMB was administered at $1.5 \mathrm{mg} / \mathrm{kg} /$ day (A1.5) intraperitoneally. All the treatments began $24 \mathrm{~h}$ after infection and continued for 7 days. For tissue burden studies, we did a second experiment under the conditions described above, and the day after treatment finished, five animals for each strain and each treatment were sacrificed. Kidneys, spleens, and liver were removed aseptically, weighed, and homogenized in $2 \mathrm{ml}$ of saline. Serial 10-fold dilutions were plated on SDA plates to determine numbers of CFU per gram, and plates were incubated at $35^{\circ} \mathrm{C}$ for $48 \mathrm{~h}$.

Survival rates were evaluated by the Kaplan-Meier test with Graph Pad Prism software for Windows. CFU counts were analyzed by the Mann-Whitney U test using SPSS 11.5 for Windows.

In vitro results. VRC showed very low MICs for both strains, IHEM 17910 and IHEM 9325 (0.06 and $0.03 \mu \mathrm{g} / \mathrm{ml}$, respectively). The AMB MIC for both strains was $1 \mu \mathrm{g} / \mathrm{ml}$.

In vivo results. For strain IHEM 17910, A1.5 surprisingly decreased survival relative to that of the control group $(P=$ 0.009 ) and V5 was not able to improve the survival of the control group $(P=0.2034)$. V10 prolonged survival relative to that of the control group $(P=0.0052)$, A1.5 $(P=0.0058)$, and V5 $(P=0.0069)$. Survival with V10 was $83.3 \%$. For strain IHEM 9325, survival was improved over that of the control group by A1.5, V5, and V10 $(P=0.0047, P=0.0082$, and $P=$ 0.0047 , respectively). No significant mean survival time differences between V5 and V10 were observed for this strain $(P=$ 0.0736). Only V10 prolonged survival relative to that with A1.5, attaining $100 \%$ survival $(P=0.0058)$ (Fig. 1$)$

A1.5 did not reduce the fungal load in kidneys, spleens, and livers of animals infected with strain IHEM 17910 However, for strain IHEM 9325, this drug reduced the fun- 

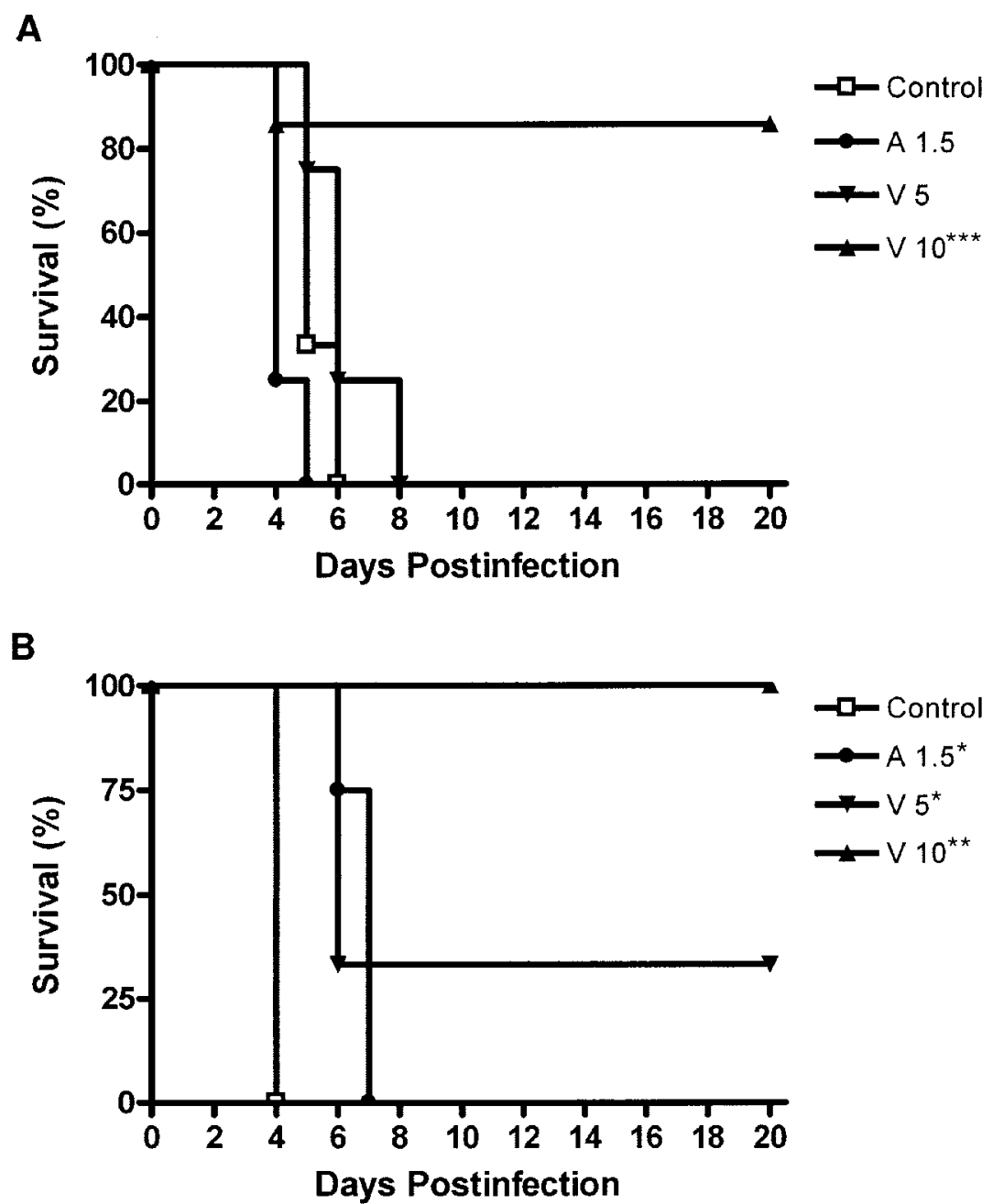

FIG. 1. Cumulative mortality of guinea pigs $(n=6)$ infected with T. asahii IHEM 17910 (A) or T. asahii IHEM 9325 (B) and given the indicated treatments. $* P<0.05$ versus control; $* \star, P<0.05$ versus control and A1.5; $* \star *, P<0.05$ versus V5.

gal loads in the three organs relative to those for the control group $(P<0.05)$. V5 for strain IHEM 17910 was able to reduce fungal loads significantly only in the kidneys and liver in comparison to the control group and A1.5. However, for strain IHEM 9325, V5 was able to reduce the fungal load in the liver only relative to that of the control group $(P<$ $0.05)$, not versus A1.5. V10 significantly reduced tissue burdens for the two strains in comparison to controls and to the other two treatments (Fig. 2).

To our knowledge, this is the first report of disseminated trichosporonosis in a guinea pig model. The lack of efficacy of AMB observed here agrees with previous work using another animal model (16) and with clinical data (9). However, in some clinical cases, after failure of AMB and fluconazole therapy, the infection improved with VRC $(3,9)$. Our results confirmed the effectiveness of this drug $(3,9)$.

Pharmacodynamic parameters have proved to be useful in predicting antifungal efficacy (2). For azoles, values of the AUC (the 24-h area under the concentration-time curve)/MIC ratio over 25 are associated with a good outcome (2). In guinea pigs, the AUC for VRC at $10 \mathrm{mg} / \mathrm{kg}$ given once a day for 7 days is 29.0 (15). Consequently, the drug AUC/MIC ratio in our study was clearly superior to 25 , even considering that the plasma protein binding of VRC in guinea pigs is $45 \%$ (15).

In summary, VRC has shown efficacy against systemic trichosporonosis and may represent an important advance in the therapy of this disease.

This work was supported by a grant from Fondo de Investigaciones Sanitarias from the Ministerio de Sanidad y Consumo of Spain (PI 050031).

\section{REFERENCES}

1. Anaissie, E. J., G. P. Bodey, H. Kantarjian, J. Ro, S. E. Vartivarian, R. Hopfer, J. Hoy, and K. Rolston. 1989. New spectrum of fungal infections in patients with cancer. Rev. Infect. Dis. 11:369-378.

2. Andes, D., K. Marchillo, T. Stamstad, and R. Conklin. 2003. In vivo pharmacokinetics and pharmacodynamics of a new triazole, voriconazole, in a murine candidiasis model. Antimicrob. Agents Chemother. 47:3165-3169.

3. Antachopoulos, C., E. Papakonstantinou, J. Dotis, E. Bibashi, M. Tamiolaki, D. Koliouskas, and E. Roilides. 2005. Fungemia due to Trichosporon asahii in a neutropenic child refractory to amphotericin B: clearance with voriconazole. J. Pedriatr. Hematol. Oncol. 27:283-285.

4. Cawley, M. J., G. R. Braxton, L. R. Haith, K. J. Reilly, R. E. Guilday, and M. L. Patton. 2000. Trichosporon beigelii infection: experience in a regional burn center. Burns 26:483-486. 
A

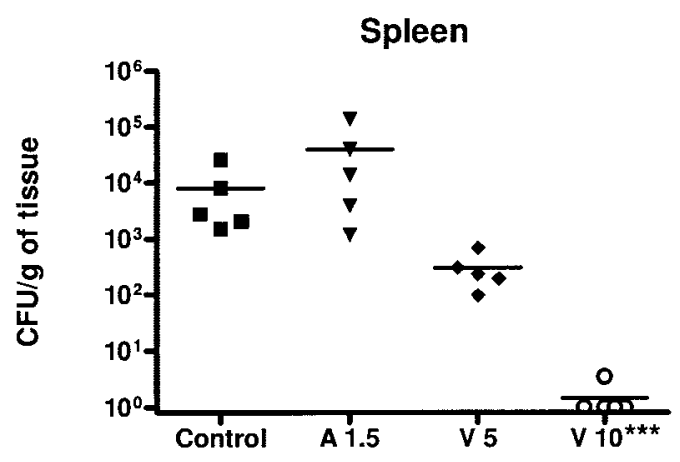

Liver

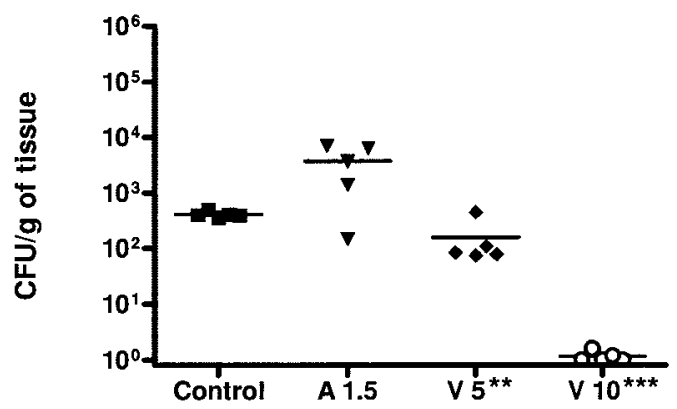

Kidneys

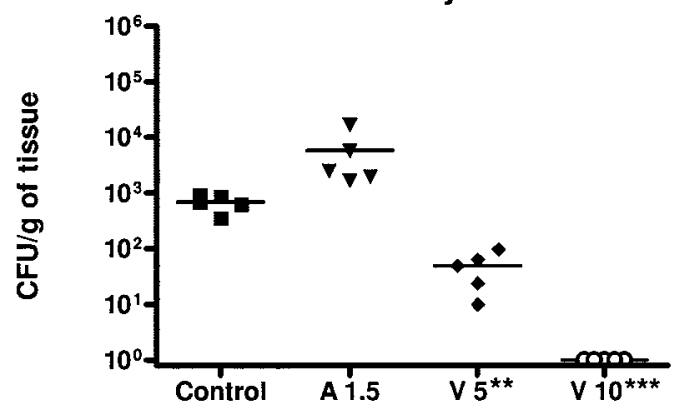

B

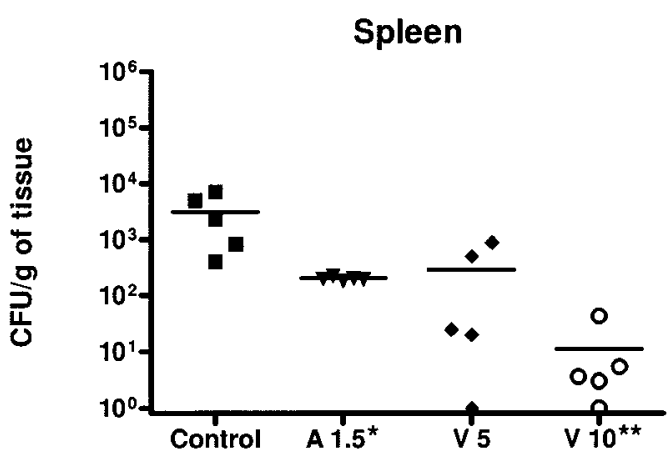

Liver

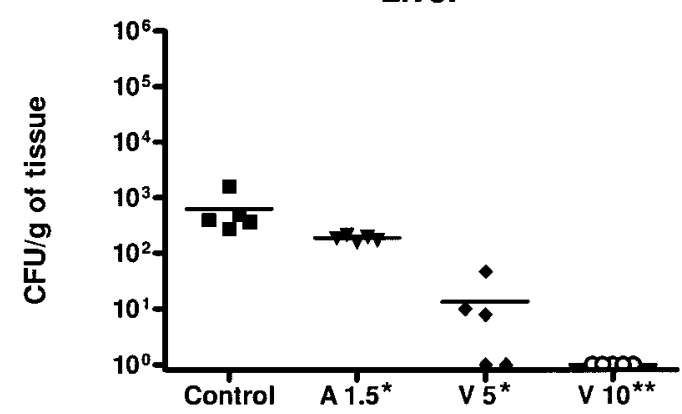

Kidneys

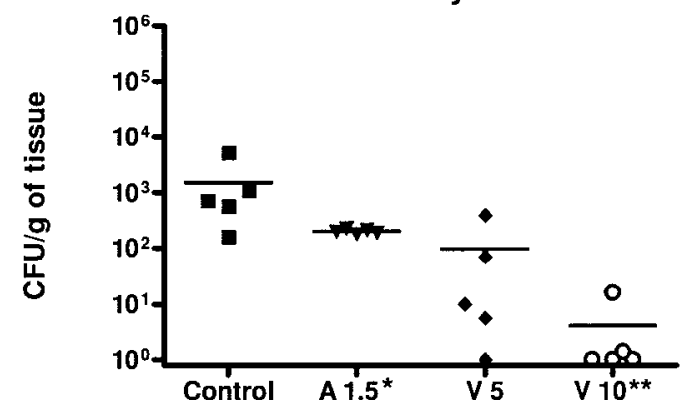

FIG. 2. Effects of the antifungal treatments on colony counts of T. asahii strains IHEM 17910 (A) and IHEM 9325 (B) in spleens, livers, and kidneys of guinea pigs. *, $P<0.05$ versus control; **, $P<0.05$ versus control and A1.5; $* * *, P<0.05$ versus V5. Horizontal lines indicate mean values.

5. Chandrasekar, P. H., J. Cutright, and E. Manavathu. 2000. Efficacy of voriconazole against invasive pulmonary aspergillosis in a guinea pig model J. Antimicrob. Chemother. 45:673-676.

6. Ebright, J. R., M. R. Fairfax, and J. A. Vazquez. 2001. Trichosporon asahii, a non-Candida yeast that caused fatal septic shock in a patient without cancer or neutropenia. Clin. Infect. Dis. 33:28-30.

7. Espinel-Ingroff, A. 1998. In vitro activity of the new triazole voriconazole (UK-109,496) against opportunistic filamentous and dimorphic fungi and common and emerging yeast pathogens. J. Clin. Microbiol. 36:198202.

8. Falk, R., D. G. Wolf, M. Shapiro, and I. Polacheck. 2003. Multidrug-resistant Trichosporon asahii isolates are susceptible to voriconazole. J. Clin. Microbiol. 41:911.

9. Fournier, S., W. Pavageau, M. Feuillhade, S. Deplus, A. M. Zagdanski, O. Verola, H. Dombret, and U. M. Molina. 2002. Use of voriconazole to successfully treat disseminated Trichosporon asahii infection in a patient with acute myeloid leukemia. Eur. J. Clin. Microbiol. Infect. Dis. 21:892-896.
10. Groll, A. H., and T. J. Walsh. 2001. Uncommon opportunistic fungi: new nosocomial threats. Clin. Microbiol. Infect. 7:824.

11. Guého, E., M. T. Smith, G. S. de Hoog, G. Billon-Grand, R. Christen, and W. H. Batenburg-van der Vegte. 1992. Contributions to a revision of the genus Trichosporon. Antonie Leeuwenhoek 62:289-316.

12. Itoh, T., H. Hosokawa, U. Kohdera, N. Toyazaki, and Y. Asada. 1996. Disseminated infection with Trichosporon asahii. Mycoses 39:195-199.

13. Moretti-Branchini, M. L., K. Fukushima, A. Z. Schreiber, K. Nishimura, P. M. Papaiordanou, P. Trabasso, R. Tanaka, and M. Miyaji. 2001. Trichosporon species infection in bone marrow transplanted patients. Diagn. Microbiol. Infect. Dis. 39:161-164.

14. National Committee for Clinical Laboratory Standards. 2002. Reference method for broth dilution antifungal susceptibility testing of yeasts. Approved standard M27-A2, 2nd ed. National Committee for Clinical Laboratory Standards, Wayne, $\mathrm{Pa}$.

15. Roffey, S. J., S. Cole, P. Comby, D. Gibson, S. G. Jezequel, A. N. R. Nedderman, D. A. Smith, D. K. Walker, and N. Wood. 2003. The dispo- 
sition of voriconazole in mouse, rat, rabbit, guinea pig, dog and human. Drug Metab. Dispos. 31:731-741.

16. Serena, C., F. J. Pastor, F. Gilgado, E. Mayayo, and J. Guarro. 2005. Efficacy of micafungin in combination with other drugs in a murine model of disseminated trichosporonosis. Antimicrob. Agents Chemother. 49:497-502.

17. Serena, C., F. J. Pastor, M. Ortoneda, J. Capilla, N. Nolard, and J. Guarro 2004. In vitro antifungal susceptibility of uncommon basidiomycetous yeasts. Antimicrob. Agents Chemother. 48:2724-2726.

18. Tashiro, T., H. Nagai, H. Nagaoka, Y. Goto, P. Kamberi, and M. Nasu. 1995 Trichosporon beigelii pneumonia in patients with hematologic malignancies. Chest 108:190-195.

19. Uzun, O., S. Arikan, S. Kocagoz, B. Sancak, and S. Unal. 2000. Susceptibility testing of voriconazole, fluconazole, itraconazole and amphotericin B against yeast isolates in a Turkish university hospital and effect of time of reading. Diagn. Microbiol. Infect. Dis. 38:101-107.

20. Vasta, S., M. Menozzi, R. Scime, A. Indovina, A. Speciale, G. Liberti, C. Spano, and I. Majolino. 1993. Central catheter infection by Trichosporon beigelii after autologous blood stem cell transplantation. A case report and review of the literature. Haematologica 78:64-67.

21. Walsh, T. J., K. R. Newman, M. Moody, R. C. Wharton, and J. C. Wade. 1986. Trichosporonosis in patients with neoplastic disease. Medicine (Baltimore) 65:268-279.

22. Walsh, T. J., G. P. Melcher, M. G. Rinaldi, J. Lecciones, D. A. McGough, P. Kelly, J. Lee, D. Callender, M. Rubin, and P. A. Pizzo. 1990. Trichosporon beigelii, an emerging pathogen resistant to amphotericin B. J. Clin. Microbiol. 28:1616-1622. 